temente, tanto la suciedad acumulada como la humedad que ha provocado el destensamiento del lienzo y, por consiguiente, el craquelado de la superficie pictórica, lo desvirtúan.

En lo cronológico sólo cabe apuntar que hemos de estar ante una pintura ejecutada por la primera mitad de la década de los sesenta, antes de la realización de su encargo para la Merced Calzada de Madrid (1667-1668), ya que existen ciertas similitudes estilísticas con pinturas inmediatamente anteriores a éstas, como el citado San José con el Niño, San Juanito y dos ángeles o el San Juan Bautista subastado en la sala La Habana en abril del año 2000.

Natalia Delgado Martínez

\title{
EL MARTIRIO DE SAN PELAYO: UNA OBRA DESCONOCIDA DEL PINTOR MARTÍN AMIGO EN BELENDIZ (BIZKAIA).
}

Dentro del cada vez más difundido y revalorizado panorama de la pintura barroca desarrollada en el País Vasco ${ }^{1}$ nos reencontramos aquí con una de sus figuras señeras durante el siglo XVII. Concretamente hablamos de Martín Amigo, pintor de origen alavés y vecino de Bilbao durante gran parte de su vida, a cuya personalidad y obra artística nos acercó en su momento el profesor Barrio Loza ${ }^{2}$. Volvemos a él con ocasión de presentar ahora un cuadro inédito conservado en la ermita de San Pelayo de Belendiz en la localidad vizcaína de Arratzu a cuya parroquia de Santo Tomás Apóstol sirve aquélla como aneja. Se trata de un óleo sobre lienzo que reproduce el martirio del santo titular, de aproximadamente $1,50 \times 2,20$ metros y regular estado de conservación, y que está firmado («Amigo ft.») y fechado (1680) en su ángulo inferior derecho. Además de acercarnos al cuadro desde diferentes ángulos, su análisis nos servirá también para intentar redondear el perfil artístico y biográfico de un artista perteneciente al pleno barroco, que da el salto del oficio de pintor-dorador desarrollado por su familia a la gran pintura, la de caballete, en la que se nos muestra dotado de una gran cultura visual al componer «historias» mezclando diferentes fuentes gráficas.

Desconocemos cómo pudo llegar a este pequeño templo una obra del interés que atesora la que comentamos ya que no tenemos constancia documental del nombre del comitente o los avatares históricos que la condujeron a su actual ubicación pero es posible que fuese el señor de la Torre de Belendiz, históricamente relacionada con la ermita y de la que está separada por escasos metros, quien se encargase de dotar al templo de la imagen del patrón que, por otra parte, aparece estrechamente relacionado con el Camino de Santiago y la cristianización del norte peninsular ${ }^{3}$.

\footnotetext{
${ }^{1}$ Tabar Anitua, F.: «La pintura del Barroco en Euskal Herria. Arte local e importado», Ondare, Donostia-San Sebastián, $\mathrm{n}^{\mathrm{o}}$ 19, 2000, pp. 117-149. Nos ofrece una síntesis de la pintura barroca del País Vasco y Navarra. Un posterior acercamiento lo tenemos en Vélez Chaurri, J.J. y Echeverría Goñi, P.L.: «Pintura barroca con vinculación histórica al País Vasco» en Oropesa, M. (Comisaria): Luces del Barroco. Pintura y escultura del siglo xVII en España (Catálogo de la exposición), Vitoria-Gasteiz, Fundación Caja Vital Kutxa y Departamento de Cultura de la Diputación Foral de Álava, 2002, pp. 21-31.

${ }^{2}$ Barrio Loza, J.A.: «Nota sobre un pintor barroco vasco mal conocido: Martín Amigo», Urtekaria/Anuario (Museo de Bellas Artes de Bilbao/Bilboko Arte Ederretako Museoa), Bilbao, 1989, pp. 35-40. Al reconocimiento de su importancia en la pintura barroca vasca han contribuido después tanto Pérez Sánchez, A.E.: Pintura barroca en España, 1600-1750, Madrid, Cátedra, 1992, p. 347 como Tabar Anitua, F.: Op. Cit., p. 126 y Vélez Chaurri, J.J. y Echeverría Goñi, P.L.: $O p$. Cit., pp. 30-31.

${ }^{3}$ Arregi, G.: Ermitas de Bizkaia, tomo I, Diputación Foral de Bizkaia, Bilbao, 1987, p. 43. Refiere que según Iturriza, historiador vizcaíno del siglo xvIII, fue fundado por la Casa solar de Belendiz en la centuria anterior. Realmente lo que obedece a ésta es la reforma del edificio pues ciertos elementos, como el arco de ingreso, nos hablan de su construcción durante el Gótico, época a la que también corresponde la mencionada Torre. A la relación de Pelayo con la ruta jacobea, nos acerca por ejemplo, Portilla, M.J.: Una ruta europea. Por Álava, a Compostela. Del Paso de San Adrián, al Ebro,
}

$A E A$, LXXVII, 2004, 308, pp. 411 a 438 
Sea como fuere, el hecho es que nos encontramos ante una nueva e importante aportación a la escasa obra pictórica barroca conservada en el Señorío, con el valor añadido de incorporarse al exiguo catálogo de las pinturas salidas de los pinceles de Amigo que hoy se encuentran dispersas por diferentes iglesias y museos del Estado y que nos muestran a un pintor que, teniendo en cuenta la calidad de su producción conservada, se encuentra por encima de los que trabajan en Bizkaia por las mismas fechas ${ }^{4}$.

A tenor de la documentación conservada, y aunque se conoce algún caso en que, como era habitual entre la mayoría de los pintores barrocos que actuaban en nuestro territorio histórico, participó en la policromía y dorado de esculturas y retablos ${ }^{5}$, no parece ser esa su tarea profesional primordial y sí la de pintor de caballete. Además de la categoría de sus propias obras apoyan este juicio otros aspectos de su biografía como su formación junto al pintor húngaro János Privitzer del que hablaremos más adelante, la importancia de las instituciones que solicitan sus obras, la temática de éstas en la que no faltan las de carácter profano y la posesión de libros y estampas que le ayudan, como veremos, en su quehacer pictórico.

Un testimonio directo de su dedicación nos lo proporcionan sus capitulaciones matrimoniales con Luisa Moreno Ybarra realizadas en Bilbao el 23 de febrero de $1672^{6}$. Martín Amigo aporta a su matrimonio con esta mujer, de buena posición social y económica, los materiales de su «arte de pintar» como aceite de linaza, algunas varas de lienzo o diferentes «drogas de colores» así como abundantes pinturas que había comenzado a elaborar y en las que observamos que predominan las de carácter religioso. Entre las de otra índole aparecen señalados algunos paisajes como dos plazas de Madrid o «un Bilvao», un «retrato del natural» y una tela de carácter mitológico como lo es el «quadro de una bara de Acteón y Diana». A la hora de elaborar algunas de estas pinturas se sirvió de diferentes libros que el propio pintor nos refiere en este inventario tales como «un Oracio», «otro libro del testamento nuevo y viejo», «dos obidios» alguno de los cuales suponemos que sería Las metamorfosis, obra en la que se inspiraría para realizar el referido cuadro de Acteón y Diana como en su momento lo hicieron otros pintores como Tiziano, «un libro de francisco pacheco»y, lo que a nosotros más nos interesa disponía también de dos libros «de varias estampas».

Es de sobra conocida la utilización de grabados o estampas como fuente gráfica para la realización de los temas más demandados por la clientela por parte de los pintores barrocos españoles ${ }^{7}$. Algunos las reproducían literalmente a través de la habitual inversión de la escena grabada mientras otros, los más avezados, se servían de varias de ellas para componer un tema «ad hoc», una síntesis de elementos que satisficiesen el gusto del promotor y para que, como

Diputación Foral de Álava, Vitoria-Gasteiz, 1991, p. 17. Uno de los itinerarios del Camino que atraviesa Bizkaia proveniente de Gipuzkoa pasa en su trayecto hacia Gernika por las cercanías de la ermita que nos ocupa.

${ }^{4}$ Barrio Loza, J.A.: Op. Cit., pp. 38-39. Este mismo autor, junto a Valverde Peña (Barrio Loza, J.A. y Valverde Peña, J.R.: «Jesusen Lagundiko ikastetxeetako erretaula eta pinturak/Retablos y pinturas en los colegios de la Compañía de Jesús», en AA.VV.: Jesusen Lagundia Bizkaian/La Compañía de Jesús en Bizkaia (Catálogo de la exposición), Bilbao, 1991, p. 83) apunta por primera vez la posibilidad de que también sean obra de Amigo los lienzos de San Ignacio de Loyola, San Francisco Javier, San Pedro, San Pablo, San Agustín y Santo Domingo de Guzmán que, dispuestos formando parejas y en el caso de los apóstoles siguiendo modelos de Ribera, adornan el retablo mayor de la iglesia bilbaína de los Santos Juanes. 72.

${ }^{5}$ Barrio Loza, J.A.: «Nota...», Op. Cit., p. 38 y Zorrozua Santisteban, J.: El retablo barroco en Bizkaia, Bilbao, 1998, p.

${ }^{6}$ Archivo Histórico Provincial de Vizcaya, Protocolos Notariales, Felipe de Villalantes, Leg. 3799, fs. 100-100v'.

${ }^{7}$ Pérez Sánchez, A.E.: De pintura y pintores: la configuración de los modelos visuales en la pintura española, Madrid, Alianza Editorial, 1993. Se le debe el inicio de una fecunda línea de investigación que tiene su brillante continuación en Navarrete Prieto, B.: La pintura andaluza del siglo XvII y sus fuentes grabadas, Madrid, Fundación de Apoyo a la Historia del Arte Hispánico, 1998. De la influencia de los grabados en otras obras barrocas vizcaínas nos habla, por ejemplo, Morente Luque, F.: «Influencias rubenianas en la pintura de Nicolás Antonio de la Cuadra a través de los grabados. La serie de la Vida de la Virgen de la Casa de la Misericordia de Bilbao», Ondare, Donostia-San Sebastián, n 19, 2000, pp. 613620 .

$A E A$, LXXVII, 2004, 308, pp. 411 a 438 
escribe Pacheco en su Arte de la pintura «se les deba, por lo menos, la composición, y de tantas cosas ajenas hagan un buen todo» ${ }^{8}$. El propio Martín Amigo realiza tanto copias idénticas como adaptaciones e, incluso, en alguna ocasión prefiere elaborar temas originales a partir de la combinación de diversas fuentes grabadas. Tal y como ocurre en la obra que nos ocupa veremos que fundamentalmente hace uso de composiciones manieristas italianas que se encargan de reproducir y difundir los grabadores flamencos.

El lienzo que nos interesa tiene como base literaria la cruenta historia del mártir Pelayo que hay que enmarcar en el ambiente de la época contrarreformista. En este periodo histórico se elogia la vida y milagros de los santos como ejemplos de vida cristiana, exaltación que en el mundo del arte tiene su reflejo en la gran cantidad de obras que reproducen los suplicios que tuvieron que padecer. En este caso es el jesuita Jean de Croiset ${ }^{9}$ uno de los encargados de referirnos los avatares del joven y hermoso mártir. Éste, sobrino de Hermoigio, Obispo de Tuy, llegó a Córdoba como rehén o garantía del pago del rescate de su tío quien había sido hecho prisionero en Galicia por las tropas de Abderramán III. El 26 de junio del año 925, y al no renegar Pelayo de su fe cristiana, el citado califa ordenará que se le despedace y se echen sus restos al río Guadalquivir.

La escena que reproducen los pinceles de Amigo (Fig. 1) se desarrolla en el interior de la lóbrega prisión a la que Pelayo fue conducido tras no acceder a los deseos del mandatario árabe y en la que está siendo torturado y desmembrado a golpe de espada. Al carecer nuestro pintor de una fuente directa en la que basarse procede a la invención del tema recurriendo a grabados que desarrollan otros como la Flagelación o la Resurrección de Cristo, y que le proporcionan personajes y elementos cercanos con los que plasmar el martirio que experimentó San Pelayo. Así, el pintor vasco aprovecha la composición circular que suele generar la referida escena pasional sustituyendo los látigos o flagelos de los sayones por espadas que cercenan el resplandeciente cuerpo del santo gallego. Éste, vestido con una túnica blanca y con la vista dirigida hacía lo alto a modo de un Cristo Resucitado, se sitúa en el centro de la pintura sobre una tarima de madera y permanece izado por una cuerda que un verdugo en la penumbra se encarga de tensar. Como ya hemos señalado, a su alrededor se colocan otros tres sayones que, con espadas y en diversas actitudes y posturas, proceden a cortar los miembros del mártir. Todo ello transcurre ante la atenta mirada del califa que, caracterizado con cetro y turbante, observa el martirio desde un murete situado en el ángulo superior derecho, apoyado cómodamente sobre un cojín de color rojo.

Otros elementos interesantes en esta obra los encontramos en un primer plano: en un lado vemos un balaustre en el que reposan las vestiduras de Pelayo y en cuya base aparece la firma y fecha de la obra que analizamos y, en el otro y compensando el anterior, Amigo dispone la figura de un perro que está comiendo parte de una pierna del santo mientras que otro de sus miembros ya cortados, un antebrazo sanguinolento, yace en el escalón de acceso a la plataforma donde se desarrolla la terrible escena.

Entre los diversos grabados que para pintar esta tela empleó Amigo hemos reconocido algunos debidos a Cornelis Cort, Aegidius Sadeler II y Boetius á Bolswert. Para realizar la figura del santo creemos que se inspira en la imagen de Cristo que aparece en La Resurrección de Cristo que, sobre composición de Giulio Clovio, realizó el primero de ellos en 1569 (Fig. 2). La figura de uno de los sayones, en concreto el que aparece de espaldas en primer plano vestido con calzón corto y gorro de color rojo, es una copia literal de la que podemos ver en $L a$

\footnotetext{
${ }^{8}$ Pacheco, F.: Arte de la pintura (edic. de Bonaventura Basegoda i Hugas), Cátedra, Madrid, 1990, p. 434.

${ }^{9}$ Croiset, J. de: Año christiano o exercicios devotos para todos los días del año, Madrid, tomo II, ed. 1901, pp. 956-
} 957

AEA, LXXVII, 2004, 308, pp. 411 a 438 

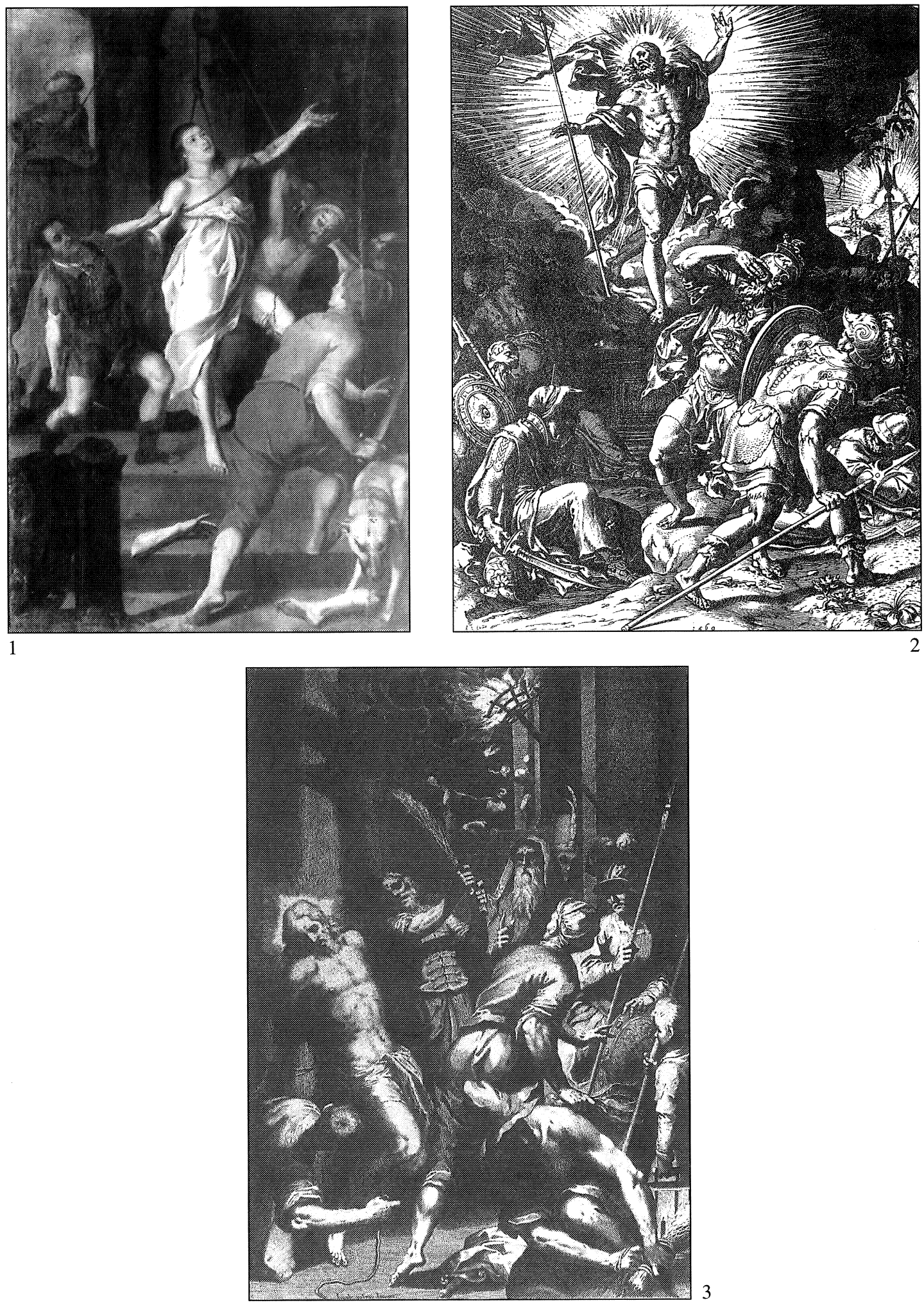

Fig. 1. Martín Amigo: El martirio de San Pelayo. Belendiz (Bizkaia)

Fig. 2. Cornelis Cort. La Resurrección. Estampa. Diseño de Giulio Clovio.

Fig. 3. Aegidius Sadeler II. La Flagelación. Estampa. Diseño de Jacobo Palma.

$A E A$, LXXVII, 2004, 308, pp. 411 a 438 


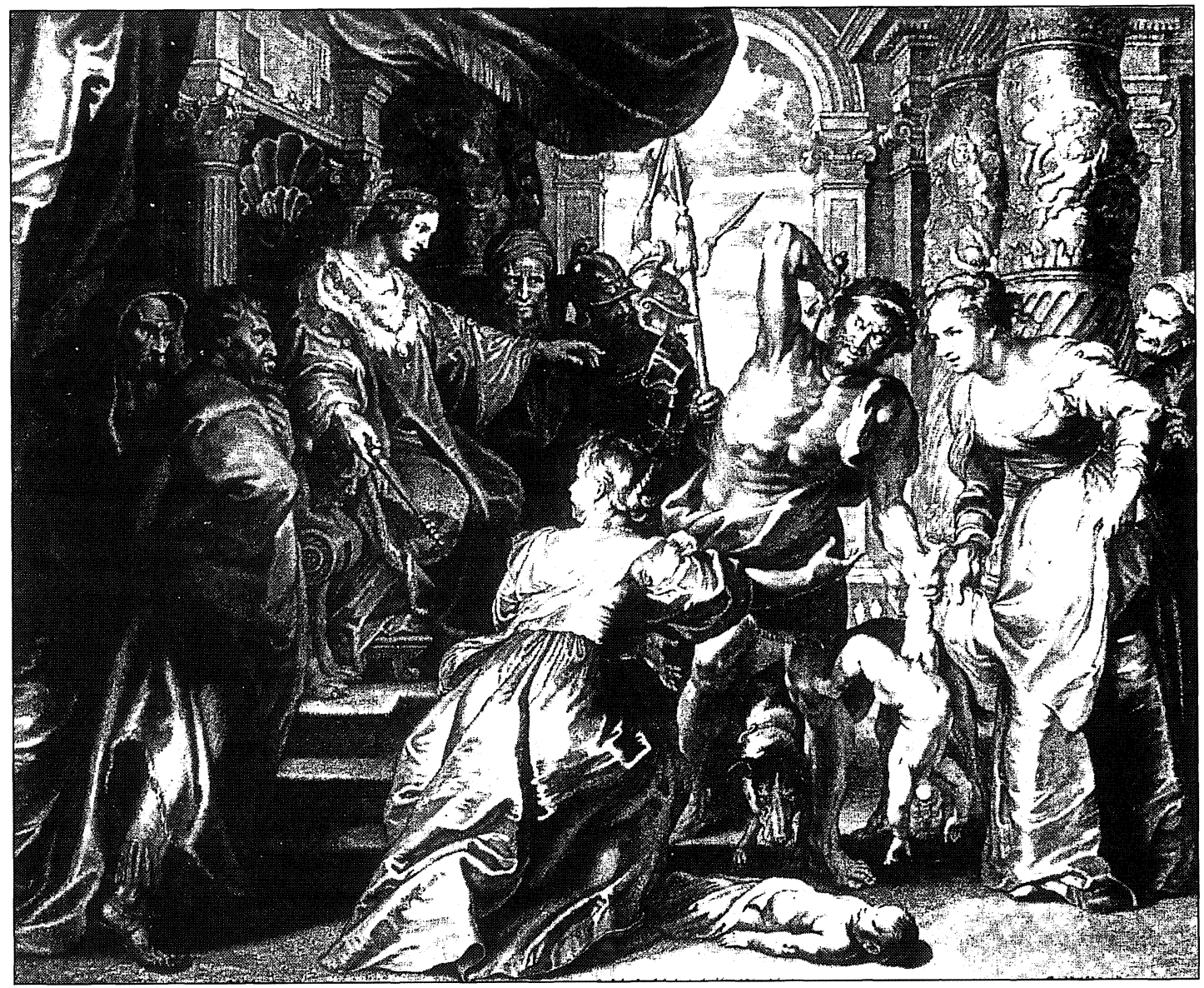

Fig. 4. Boetius à Bolswert. El juicio de Salomón. Estampa. Diseño de P. P. Rubens.

Flagelación que Sadeler II grabó en 1594 (Fig. 3) inspirándose en una obra de Jacobo Palma ${ }^{10}$. Por último y para la imagen del verdugo que, en forzada postura y levantando su brazo izquierdo, va a proceder a seguir cortando una de las piernas del mártir se inspira directamente en la representación del esbirro que va a partir el niño que podemos contemplar en el grabado (Fig. 4) que el citado Bolswert realizó del cuadro de Rubens titulado El juicio de Salomón ${ }^{11}$.

Para la realización de otros aspectos se basa igualmente en diversas fuentes grabadas que son más difíciles de precisar aunque, por citar otro ejemplo, la representación de Abderramán III podría estar perfectamente inspirada en la figura de Pilatos o en las de los fariseos o miembros del Sanedrín que suelen aparecer en las escenas de la Flagelación u otras del ciclo de la Pasión de Cristo o, en esta ocasión y como creemos, en la figura de Herodes que contempla

\footnotetext{
${ }^{10}$ Así lo podemos apreciar en Bartsch, A.: The Illustrated Bartsch, New York, vol. 52, 1986, p. 114 e Ibídem, vol. 72 , part 1, 1997, p. 73. El mismo sayón es visible en La Flagelación que Tabar propone atribuir a Juan del Castillo y se conserva en una colección particular de Vitoria-Gasteiz (Tabar Anitua, F.: Barroco importado en Álava. Escultura y pintura (Catálogo de la exposición), Diputación Foral de Álava, Vitoria-Gasteiz, 1995, pp. 115-117 y fig. 53). Es una pintura compuesta a partir de otra Flagelación grabada por Aegidius Sadeler II en 1593 (Bartsch, A.: Op. Cit., vol. 72, part 1, 1997, p. 74.) en la que Del Castillo sustituye al verdugo que aparece de espaldas en la misma por este otro que al igual que en el lienzo de San Pelayo viste calzas y gorro de color rojo y que Tabar relaciona con la pintura de Bassano.

" D'Hulst, R.-A. y Vandeven, M.: Rubens: The Old Testament (Corpus Rubenianum Ludwig Burchard: Part 3), Harvey Miller Publisher, New York, 1989, pp. 146-150 y fig. 102. De la utilización de este grabado para la realización de otras pinturas dan cuenta Pérez Sánchez, A.E.: De pintura y pintores, Op. Cit., pp. 85-86 y Navarrete Prieto, B.: Op. cit., pp. $210-211$.
}

AEA, LXXVII, 2004, 308, pp. 411 a 438 
desde una balconada la decapitación de Santiago el Mayor en un grabado debido a Philips Galle sobre dibujo de Stradanus ${ }^{12}$.

Entre los aspectos técnicos y estilísticos del cuadro tenemos su carácter netamente barroco derivado del gran dinamismo inherente al violento tema representado logrado a través del establecimiento de diferentes diagonales, del trazado de una composición en zigzag que partiendo del pie del sayón situado de espaldas culmina en la mano alzada del mártir y mediante el predominio de un enérgico contraste de colores entre los que destaca el rojo presente, además de en la sangre, en las vestiduras de algunos verdugos. Éstos, como es usual, muestran semblantes patibularios y entre ellos sobresale, por portar ropajes de la época en que se pinta el lienzo y presentar un rostro más realista, el situado bajo el califa Abderramán. Destacaríamos también el buen tratamiento realizado de las sombras, de los efectos de la perspectiva y, en general, los adecuados estudios anatómicos. En definitiva se trata de una pintura tardotenebrista que muestra cierta luminosidad gracias a la luz que penetra por el mirador al que se asoma el dignatario árabe y a la irradiada por el cuerpo del santo, y que cuenta además con rasgos naturalistas como el cuerpo semidesnudo de éste, la cara y la indumentaria del verdugo situado a su izquierda y el brillante colorido ya referido. En las figuras principales muestra aún una pintura dibujística, compacta, mientras que se torna más suelta en las de carácter secundario.

Estilísticamente, como ya ha sido señalado por los autores que previamente se han acercado a la personalidad artística de Amigo y corroboran varios de los aspectos comentados, se trata de una pintura que, además de mostrarse muy dependiente de las estampas que reproducen sobre todo modelos manieristas, podemos relacionar con la desarrollada en la Corte durante la segunda mitad del XVII entre otros por Carreño Miranda, Herrera o Rizi, y por ello también con la pintura flamenca y veneciana a través de algunos de los maestros que más influyeron en ellos como Tiziano, Rubens y Van Dyck. Pero estos últimos componentes en el caso del pintor vasco pueden derivar más que de la contemplación directa de la obra de todos ellos en Madrid de la formación que, tras los primeros pasos que daría junto a su padre Juan y su abuelo, el pintor-dorador Diego Pérez de Cisneros, realizaría con János Privitzer. Este retratista húngaro es el responsable de la formación de varios de los maestros activos en Bizkaia en la segunda mitad del XviI como Juan de Berni o el propio Amigo que sabemos fueron sus aprendices ${ }^{13}$. Priviser, tal y como firma en diversos documentos vizcaínos, residió durante algún tiempo en Londres a donde quizás acudió, como otros artistas de la época, huyendo de la Guerra de los Treinta Años que asoló gran parte de Europa entre los años 1618-1648. Allí, como lo refieren diversos autores, realizó retratos para la alta sociedad entre ellos el del embajador español Don Diego Sarmiento de Acuña (conde de Gondomar), en $1621^{14}$, y es donde bien directamente como colaborador de Van Dyck, bien a través de la visión de las obras de

\footnotetext{
${ }^{12}$ Bartsch, A.: Op. Cit., New York, vol. 56, 1987, p. 169.

${ }^{13}$ Archivo Foral de Bizkaia, Corregimiento, Leg. 1386/18. Es un pleito del año 1677 promovido por Juan de Berni, maestro pintor vecino de Bilbao, contra Pedro Alonso de Hontanilla, oficial de dicho oficio, sobre cumplimiento de un contrato de aprendizaje y en el que también le acusa de haberle robado diversas herramientas de su oficio: Un caballete, una paleta en donde se ponen los colores... Estas últimas le fueron dejadas a Berni por Priviser entre otras cosas «por haber sido su criado». Amigo participa como testigo, el 9 de marzo del referido 1677, declarando tener unos 40 años y señala, junto a lo anterior, que él «trabajó con ellas hace 20 años poco más o menos siendo aprendiz de Juan Prebiser pintor que fue de esta villa...».

${ }^{14}$ Es la única obra que, firmada por «Johannes pribizer», se conoce por el momento en España habiéndose expuesto tanto en Madrid (Brown, J. y Elliot, J.H. (Directores.): La almoneda del siglo. Relaciones artísticas entre España y Gran Breta$\tilde{n} a, 1604-1655$ (Catálogo de la exposición), Museo del Prado, Madrid, 2002, pp. 184-187) como en Valladolid (Urrea Fernández, J.(Director): Valladolid. Capital de la Corte (1601-1606) (Catálogo de la exposición), Cámara, Valladolid, 2002, pp.92-95). Bénézit, E.: Dictionnaire critique et documentaire des peintres..., Gründ, tomo XI, 1999, p. 261. En esta última edición del conocido compendio de artistas se le cita como Johann Priwitzer (Privisier, Priwitzerus) y habla de una nueva obra realizada en Inglaterra, el retrato de Lucy Harrington (Condesa de Bedford) pintado en 1620.
}

$A E A$, LXXVII, 2004, 308, pp. 411 a 438 
éste pudo empaparse de su estilo que después puede percibirse en diversas pinturas debidas a su discípulo Martín Amigo.

A Privitzer (o Privisier, Priwitzer, Pribizer,...) se le localiza más tarde en Valladolid, en 1647, relacionándose con Diego Valentín Díaz ${ }^{15}$ y en Bilbao, sede de una importante colonia comercial británica, le conocemos desde 1648, año en que actúa como traductor en un pleito protagonizado por súbditos ingleses con quienes se relacionará en sucesivas ocasiones; por ejemplo en 1656, más o menos la época en la que Amigo estaría bajo sus órdenes, cuando acoge como aprendiz a un hijo de Tomás Archer, irlandés residente en la capital del Señorío ${ }^{16}$. Para finalizar hemos de comentar que, por lo indicado, es indudable que a Priviser se debe en buena parte la puesta al día de gran parte de los pintores activos en nuestro territorio durante la segunda mitad del siglo xVII, la época pictórica más brillante y productiva de toda la centuria, y en especial la del pintor cuya obra aquí nos ha interesado.

JULEN ZORROZUA SANTISTEBAN

${ }^{15}$ Brown, J. y Elliot, J.H. (Directores.): Op. Cit., p. 186 (cfr. Martí y Monsó, J.: Estudios histórico-artísticos relativos principalmente a Valladolid, Valladolid, 1898-1901, p. 6)

${ }^{16}$ Archivo Foral de Bizkaia, Corregimiento, Leg. 0875/029. Actúa como tal en el contencioso establecido en relación con una carga de bacalao entre varios mercaderes ingleses residentes en Bilbao y el maestre del navío «Expectation» de la misma nacionalidad; Ibídem, Corregimiento, Leg. 1202/20, fs. 170 y 171. En 1654 otorga junto a Juan Hueque, mercader inglés, una fianza para lograr la libertad de un compatriota presuntamente implicado en un homicidio y finalmente, el contrato de aprendizaje de Raimundo Archer por una duración de ocho años lo firma el trece de octubre de 1656 (Ibídem, Corregimiento, Leg. 0544/177).

AEA, LXXVII, 2004, 308, pp. 411 a 438 